\title{
¿Es posible una comunidad filosófica iberoamericana?
}

\author{
LUIS VILLORO \\ Instituto de Investigaciones Filosóficas \\ Universidad Nacional Autónoma de México
}

En 1898 desaparecía el último vestigio de la dominación española en América. Para España parecía el fin de su historia. Duelo, amargura, introspección de toda una generación obsesionada por la pregunta: iqué somos? lpor qué caímos? Por su parte, en América se iniciaba también un largo camino que conduciría a preguntar por su ser dependiente. Sin embargo, aquella fecha histórica abría la puerta a una transmutación en la relación entre España y América. El fin era, en realidad, un comienzo: el último día de la dominación era también el anuncio de una comunidad posible. Porque la comunidad es lo contrario a todo dominio; sólo puede darse en el reconocimiento entre iguales.

Ahora, cien años más tarde, estamos juntas, por primera vez, voces intelectuales de todos los países de lengua hispana, en el reconocimiento recíproco, único del que podría tal vez surgir algo nuevo: una comunidad filosófica iberoamericana.

Porque el simple hecho de dialogar aquí, de compartir prcocupaciones teóricas semejantes y debatirlas, implica que nos reúne, de manera expresa o implícita, la voluntad de plantear la posibilidad de una comunidad filosófica.

He dicho «plantear la posibilidad», porque no es seguro siquiera que esa comunidad pudiera mañana edificarse. $Y$ tal vez alguno de ustedes - acuciado por el demonio filosófico de la duda- podría incluso preguntarse si es deseable. Y sin embargo aquí estamos. ¿No sería saludable, entonces, iniciar estas conversaciones preguntándonos justamente por la justificación y el fin de nuestro encuentro? Si cstamos aquí movidos por la íntima esperanza de lograr una comunidad filosófica, esa pregunta podría presentar una formulación doble. Primera: ¿Cuáles serían las condiciones de posibilidad de una comunidad filosófica iberoamericana? X segunda: Aun si se cumplieran esas condiciones, ¿sería acaso descable?

Veamos la primera pregunta. Las condiciones para realizar una comunidad de pensamiento filosófico son de distintos niveles. Pasaré rápidamente sobre las condiciones materiales por ser las más obvias. Comunidad implica comunicación. Ésta es imposible sin un intercambio constante. La argumentación común, la discusión, la crítica son los caminos de la comunicación filosófica. 
Ninguna obra importante en esa disciplina pudo darse sin un diálogo continuo. Sócrates es impensable sin las discusiones interminables en Atenas, Descartes sin los dimes y diretes de científicos y filósofos, en salones y universidades de París o de La Haya, y aun un solitario como Wittgenstein no fue más que una voz en el concierto de muchas otras - algunas de ellas olvidadas- que se escuchaba en los medios intelectuales de Austria, Alemania e Inglaterra.

El intercambio se consolida en espacios sociales, en instituciones. Si en un tícmpo cumplieron esa función la Iglesia o los salones, ahora sólo la llenan las universidades. Instituciones universitarias sólidas, preocupadas por el intercambio frecuente entre filósofos, son una condición necesaria para dotar a la comunidad de un espacio. ¿Será posible ese intercambio -aún limitado en exceso-entre las instituciones universitarias de lengua española?

Pero las instituciones son importantes en la medida en que ofrezcan un campo para el reconocimiento recíproco. Porque otra condición de posibilidad de cualquier comunidad intelectual es la igualdad entre los interlocutores en el diálogo. Una comunidad intelectual no es más que una red de relaciones entre sujetos de interlocución, en la que ninguno pretende ser hablante privilegiado para que los demás sólo comenten su palabra; en ella, todos se reconocen recíprocamente como iguales y, por lo tanto, todos razonan y escuchan alternativamente.

$Y$ aquí cs donde podríamos encontrar una primera dificultad para la constítución de una comunidad filosófica iberoamericana. Al no encontrar dentro de su sociedad un diálogo que consideren de suficiente valía, quienes se inician en la filosofía suelen volver la vista a otras asociaciones que florecen en los países más desarrollados. Porque la filosofia no conoce fronteras y ningún producto de calidad puede ser desdeñado. El contacto con medios más desarrollados contribuye a menudo al rigor de nuestra labor filosófica, pero puede también desquiciarla. Aparece entonces una figura arquetípica en nuestros medios. Podríamos llamarla «el filósofo alterado». El filósofo o la filósofa alterada tiene puestos sus sentidos en las filosofías que otros crean. Es, en realidad, un consumidor de papeles. Obsesionado por no quedar fuera de los temas que circulan, se dedica con fruición a leer los últimos artículos y libros publicados de autores extranjeros; generalmente escoge un autor prestigioso para seguirlo, desmenuzario, comentarlo, venerarlo. Le interesan sólo los filósofos ampliamente citados, en alemán o en inglés de preferencia, sueña con lo que sería su consagración: ser el glosador reconocido, cuya interpretación del filósofo escogido sería tomada en cuenta en algún coloquio internacional y - colmo de los éxitos - citada a pie de página de alguna obra futura sobre el maestro. Nuestro mundillo filosófico está así poblado de comentaristas, críticos, epígonos de otros filósofos, cuya elección cambia con las modas, para razonar de nuevo sobre las razones de otros raciocinadores. De por sí, esta actividad no es forzosamente mala. Siempre han existido, en torno a los filósofos creadores, comentadores alterados. Pero consigna un hecho. La imposibilidad 
de construir con ellos una comunidad propia. El consumidor de papeles y comentador de filósofos de moda acepta para sí el papel de seguidor de una comunidad otra, a la que no pertenece. En ella ha elegido escuchar y pronunciar las palabras que respondan a palabras ajenas. No entra en una situación en que campee un reconocimiento recíproco. En realidad ha elegido su sitio: en la trastienda se siente cómodo.

Además, puesto que cada filósofo alterado ha elegido una corriente distinta o un autor preferentc, cl diálogo se establece en el círculo estrecho de los seguidores de la misma doctrina o del mismo maestro. Entre muchos comentarios de distintas obras filosóficas no puede constituirse una escuela. ¿No ha sido esta actitud un obstáculo permanente para la creación, en nuestros países, de una tradición filosófica propia?

El diálogo entre iguales requiere de una tercera condición: por distintas que sean las posiciones de los dialogantes, tienen que compartir ciertas preguntas. Preguntas, digo, no soluciones ni doctrinas. Los presocráticos tenían respuestas diferentes, pero participaban de una comunidad de pensamiento porque trataban de responder a los mismos interrogantes. Santo Tomás y San Buenaventura se inscribian en tradiciones distintas, pero respondian a cuestiones semejantes, lo mismo Hume y Kant o Russell y Wittgenstein, entre miles de ejemplos. Una comunidad filosófica exige: unidad en las preguntas, diversidad en las vías para responderlas.

¿Varian las preguntas de una comunidad filosófica a otra? Una comunidad filosófica iberoamericana itendría que plantear sus propias preguntas? Nos asomamos así a otro obstáculo real, opuesto al que señalábamos antes.

Las preguntas filosóficas se refieren a temas universales y responden a necesidades de todo individuo o grupo de nuestra especie. Pero se presentan en el seno de una cultura en un momento de su historia: cada comunidad está inmersa en un contexto distinto. La misma pregunta presenta variaciones: ante todo, las motivaciones que conducen a plantearla pueden ser disímbolas. Si las razones que aduce el filósofo pueden ser válidas para cualquier ente racional, sus motivos - psicológicos, sociales, culturales- están ligados a un contexto. De ahí que una comunidad filosófica suela dar relevancia a unas preguntas sobre otras, porque algunas expresan mejor que otras sus necesidades prioritarias. Por otra parte, aunque el tema de la pregunta sea universal, no lo es la manera de plantearlo, el enfoque con que se lo considera, los matices que se destacan y su relación con otros temas en una totalidad. Una comunidad filosófica se reconoce por esa selección y ese enfoque. Ambos dependen de una cultura.

La dependencia de las preguntas filosóficas respecto de la culturas históricas invita a hacer corresponder la reflexión con necesidades reales de nuestro entorno social. Es entonces un Ilamado a la autenticidad. Sin embargo, ha dado lugar también a una postura discutible. Es una concepción de la labor filosófica que origina en nuestros lares a otra figura arquetípica: al filósofo 
alterado se opone ahora cl «ensimismado", al devorador de papeles ajenos, el explorador de sí mismo. Para crear una comunidad propia —cavila ese filósofo o filósofa - hay que pensar justamente en lo que constituye «lo propio», es decir, lo "peculiar», lo que nos distingue de cualquier otra comunidad. Sólo así romperíamos nuestra imitación de otros pensamientos, sólo así nos libraríamos por fin de nuestra enajenación y dependencia. Como Diógenes con su linterna, el filósofo no para en la búsqueda de su ser perdido.

Esa postura sería liberadora, sin duda, si no cayera con facilidad en un equívoco. Se basa, en efecto, en dos supuestos que acepta sin demostrar: supone, en primer lugar, que existe algo «propio», esto es, que hay alguna nota o característica exclusiva de cada cultura, que no comparte con ninguna otra. Habria una «identidad" oculta por descubrir, una "realidad" debajo de las apariencias, un «ser» por encontrar. Supone, en segundo lugar, que esa peculiaridad plantearia a la filosofia preguntas distintivas que se referirian a temas exclusivos. Pero esos dos supuestos son, por lo menos, discutibles. Desde su nacimiento, en Grecia o aun en la India, la reflexión filosófica ha partido del supuesto contrario: por un lado, buscar sla urdimbre y la trama» de todo lo existente más allá de las diferencias; por el otro, diseñar los principios y límites de la razón en cualquier sujeto en que se manifieste.

Invocando la búsqueda de la propia identidad, aquella concepción puede derivar, en realidad, en el aislamicnto: desinterés por los métodos universales de la razón, desdén por los argumentos y análisis conceptuales desarrollados en otros espacios de reflexión: Suelen dejar de plantearse, entonces, los temas que han constituido el centro de la epistemología, la metafísica o la ética de todos los tiempos, para privilegiar las reflexiones sobre la propia circunstancia cultural o política. Se pasa de la argumentación rigurosa al ensayo histórico y social. De hecho, por valiosos que pudieran ser en otros aspectos, los alegatos por una filosofía así concebida rara vez han rebasado la presentación del programa de lo que debería ser «nuestra filosofia» sin llegar a desarrollarla, porque para ello tendrían que analizar de nuevo problemas que rebasan el límite de «lo propio».

Tados nosotros, creo, hemos vivido, vivimos aún, en nuestros países los dos escollos opuestos. Seguimos oscilando, hubiera dicho tal vez Ortega, entre una filosofía de Marburgo y una «filosofía del Manzanares». Porque ambos escollos tienen su parte de verdad y, por ende, su atractivo. El filósofo alterado puede caer en la enajenación, pero obedece también a la convicción de que cualquier problema filosófico nos concierne $y$, por lo tanto, no hay fronteras que lo acoten. Su error no consiste en plantear las mismas preguntas que cualquier otro filósofo, sino en no atreverse a utilizar en su análisis la propia razón sino la ajena. El ensimismado, por su parte, puede sucumbir al aislamiento, pero atiende también a la exigencia de que su filosofía exprese necesidades propias. Su error no estriba en explorar su identidad, sino en olvidar el carácter universal de ese problema. 
Las comunidades filosóficas sólo nacieron -me parece- cuando lograron superar ambas clases de escollos opuestos: la alteración en la imitación de culturas ajenas y el ensimismamiento en los propios mitos y tradiciones. Una explicación parcial de la dificultad por desarrollar una comunidad filosófica en nuestros países puede ser nuestra torpeza en bogar entre esos arrecifes contranios.

Pero si tal es nuestra situación, dcbemos plantear nuestra segunda pregunta: ¿Por qué perseguir la constitución de una comunidad que se nos escapa? ¿Vale la pena? Después de todo, muchos filósofos españoles se están planteando - según creo- una alternativa: integrarse en la comunidad más amplia de la filosofía europea, en lugar de perder su tiempo en discutir autores de lengua española. Y los latinoamericanos pronto nos veremos avasallados por la tentación de muchos, de incorporarse a otra comunidad de pensamiento más rica: la de los Estados Unidos de América. ¿Por qué entonces empeñarnos en una comunidad iberoamericana?

Podria contestar recordando viejas añoranzas: la hermandad fraguada en una tradición común, la belleza de una lengua que hace mucho salió de Castilla para transfigurarse en una multiplicidad de formas, o la riqueza de una vieja y honda cullura, sintesis a su vez de muchas otras.

Podría también invocar algunas ideas colectivas, gérmenes de utopías: en aquel lado del Atlántico, el llamado de «nuestra América», de Bolívar, de Martí; en este lado, cl ideal de la «hispanidad». O aún podría conjurar emblemas y mitos: el caballero andante en tierra de infieles, el espiritual Ariel en lucha con Calibán, el bárbaro, o aun el forjador de una «raza cósmica».

Esos son modos de expresar deseos colectivos profundos, anhelos comunes de una fraternidad posible, que trascendiera nuestras limitaciones. Encienden nuestras emociones, alimentan nuestra esperanza. Pero frente a esas razones del corazón prefiero apelar ahora, a riesgo de parecer sin alma, a razones más adecuadas a la prudencia que recomendaria un pensamiento crítico. Creo, simplemente, que una comunidad filosófica iberoamericana es un elemento que favorece la creación de una filosofía auténtica.

"Auténtico» podemos llamar a un pensamiento cuando cumple con dos condiciones: cuando es autónomo, es decir, obedece a la propia razón y no a decires ajenos. No se limita a glosar o repctir los discursos de maestros externos, los somete todos al juicio del «maestro interior». En segundo lugar, un pensamiento es "auténtico» cuando es coherente con los deseos reales y las necesidades efectivas de quienes lo sustentan. Y sólo si es auténtico es creativo.

Ahora bien, las condíciones de posibilidad de una comunidad filosófica que antes señalé podrían cumplirse en cualquicr comunidad; sin embargo, podemos alegar que facilitarían considerablemente nuestra creatividad filosófica si se cumplieran cabalmente en una comunidad que comparta la misma lengua y tradición histórica. $Y$ una comunidad filosófica tal no tendría por qué excluir su inclusión en comunidades filosóficas más amplias. 
Una comunidad de pensamiento sólo florece en una situación de intercambio de ideas, discusión de propuestas de trabajo, crítica, controversia sobre todo lo que se declara o publica. En la discusión cotidiana la producción intelectual templa su rigor y afina sus hallazgos. Ese intercambio puede, en principio, realizarse en comunidades más amplias que la de lengua castellana. Pero en la práctica, sólo en casos excepcionales, producto muchas veces de encuentros fortuitos más que de la calidad de la obra, la discusión ocasional conduce a un diálogo permanente. No solemos ser interlocutores habituales en los medios filosóficos de países más desarrollados; es frecuente que seamos en ellos entrometidas e inconstantes aves de paso, o bien, gocemos de la benevolencia y el interés cortés que se concede a un pariente de segunda clase.

Condición del diálogo - recordé antes- es el reconocimiento entre iguales. Sólo en la comunicación entre pares la interpelación del otro incita a razonar por cuenta propia, sólo entonces es un factor que conduce a la autonomía de la razón. Pues bien, esa forma de diálogo racional es posible entre creadores intelcetuales de la misma tradición cultural, porque cntre ellos el reconocimiento reciproco es un supuesto: se acepta salvo razones en contrario. En cambio, en las relaciones con otras culturas que se creen superiores, el reconocimiento no puede darse por supuesto, cs una conquista. Además, en nuestro medio cultural el otro puede interpelarnos sobre un terreno común de supuestos semejantes; en un medio cultural distinto siempre cabe la posibilidad de que la interpelación se base en supuestos no compartidos.

Una última condición de una comunidad filosófica auténtica - dije anteses la capacidad de reconocerse en preguntas compartidas. Las preguntas filosóficas responden a temas que interesan a cualquier sujeto racional, pero la selección de los temas obedece a necesidades de una comunidad dada en un contexto histórico; es obra del deseo colectivo. En la importancia que se conceda a un género de preguntas sobre otros podemos reconocer una comunidad filosófica. La selección de problemas pertinentes, por otra parte, lleva consigo el enfoque peculiar para tratarlos y los rasgos con que los presentamos. Expresa además nuestros intereses y experiencias comunes. Todo ello se desarrolla en el marco de una cultura.

Este punto no es obvio en aquellas preguntas filosóficas cuya respuesta depende de un saber incontrovertible, por ejemplo en problemas de lógica o en muchos de filosofía de la ciencia. Pero aun en esos campos, la formación de pequeños grupos que comparten la misma lengua favorece considerablemente la calidad de la producción, contribuyendo a propiciar el diálogo frecuente y la crítica recíproca.

La dependencia cultural de la filosofía es más clara en aquellos otros campos, la mayoria, que remiten para su justificación a un «conocimiento personal», es decir, a una forma de conocimiento que no puede prescindir de experiencias intersubjetivas sometidas a crítica. Tal es el caso en problemas de ética, de filosofía política, de filosofía del arte o de la religión. La marca de originalidad 
que una comunidad filosófica determinada imprime en una producción filosófica no consiste, desde luego, en el tratamiento de temas que le fueran exclusivos o en la formulación de problemas peculiares, sino en la importancia que concede a unos y a otros siguiendo deseos colectivos; se traduce entonces en un estilo, un enfoque, un modo específico de tratar problemas universales, que expresa necesidades y supuestos culturales propios. Y ésa es una marca de la autenticidad de una producción filosófica.

Hc plantcado algunas razones que podrían aducirse para justificar la construcción de una comunidad iberoamericana de filosofía. Porque ésta aún no existe cabalmentc. Sólo contamos con inicios, en determinados campos, donde ya pucde notarse el toque peculiar que respondería a nuestras preferencias. Son logros limitados. La comunidad que imaginamos es todavía un proyecto. Es asunto de elección; habría que edificarla. ¿Y qué lugar mejor que esta reunión para meditar sobre una elección semcjante?

Al llegar al término de estas palabras me percato de la escasa medida en que he podido dar respuesta a las preguntas con que las inicié. Pero entre filósofos, espero que esa falla pueda ser perdonada. Porque aunque este discurso se presente como una oración inaugural, su lenguajc ha pretendido ser filosófico. $\mathrm{Y}$ en filosofía la respuesta a una pregunta no consiste tanto en apuntar soluciones como en aclarar la pregunta misma. Sea pues ésta una invitación para que cada quien se plantee la posibilidad y la conveniencia de una comunidad filosófica iberoamericana. $Y$ esc planteamiento, ¿no constituiría ya, por sí mismo, la primera piedra en la construcción de una comunidad semejante? 


\title{
A STRAGALO
}

CULTURA DE LA ARQUTTECTURA Y LA CIUDAD

\author{
REVISTA CUATRIMESTRAL \\ I B E R O A M E R I C A N A \\ CONSEJO DE DIRECCION: \\ ANTONIO F.-ALBA/ROBERTO FERNANDEZ/FERNANDO R. DE LA FLOR/ \\ ROBERTO GOYCOOLEA/FRANCISCO LEÓN/EDUARDO SUBIRATS
}

\author{
EL EFECTO DE LA GLOBALIZACIÓN \\ Escenarios posurbanos \\ Roberto Fernainde* \\ Escenarios posurbanos \\ Joaquin Rusque Muurel \\ Globalización y nacionalismos \\ Paloma Olmedo \\ La ciudad del pensamiento único \\ Régis Debray \\ La republica despojada \\ Ruberto Goycoolea \\ Ciudad y democracia en la sociedad telemática \\ Angelique Trachanna \\ Aporias de la posmodernidad. \\ Un problems espacial y cognitivo \\ FORO ABIERTO \\ César Antonio Molina \\ Siracusa \\ RESEÑAS DF $1, O$ PUBIICADO \\ R. F \\ Guía de perplejos utbanos \\ José Labotda \\ Las fuentes de Mies \\ RELATOS DE LO VA VISTO \\ Antonio Fernándex-Älba \\ Materia y memoria. \\ Recordando a Carlos Fernándet Casado \\ Vicente Verdú \\ La maldición de las torres \\ POSIFOLIO \\ Fernando K. de la Flor \\ Presencia te una dusencia. \\ La dimensín aurática del monumento \\ y la ciudal histónica de la Edad Moderna. \\ Francisco Leôn \\ Las constantes de la tradición \\ en th pensimiento estético posvanguardista. \\ Javier Rivera Mlanco \\ El patrimonio y la restauración arquitectónica. \\ Niteves conceptos y fronteras. \\ ENGLISH INDEX AND SUMMARIES
}

Pedidos:

Conkeo: Celeste Ediciones, S. A. C Fernando VI, 8-1,"28004 Madrid. Lspaña TELÊFONO: 913100599 FAX: 913100459 E-MArl: celesteOfedecalics 